\title{
Loss of p53 in mesenchymal stem cells promotes alteration of bone remodeling through negative regulation of osteoprotegerin
}

\author{
Tania Velletri ${ }^{1,7} \cdot$ Yin Huang $\mathbb{1}^{1} \cdot$ Yu Wang $\mathbb{1}^{1} \cdot$ Qing $\mathrm{Li}^{1} \cdot$ Mingyuan $\mathrm{Hu}^{1} \cdot \mathrm{Ningxia} \mathrm{Xie}^{2,3} \cdot$ Qian Yang ${ }^{1}$. \\ Xiaodong Chen ${ }^{1} \cdot$ Qing Chen ${ }^{1}$ - Peishun Shou ${ }^{1} \cdot$ Yurun Gan ${ }^{1}$ - Eleonora Candi ${ }^{2,4}$. \\ Margherita Annicchiarico-Petruzzelli ${ }^{4}$ Massimiliano Agostini ${ }^{2} \cdot$ Huilin Yang ${ }^{5} \cdot$ Gerry Melino $^{2,6} \cdot$ Yufang Shi $\mathbb{I}^{1,2,5}$. \\ Ying Wang ${ }^{1}$
}

Received: 19 December 2019 / Revised: 8 July 2020 / Accepted: 9 July 2020

(c) The Author(s) 2020. This article is published with open access

\begin{abstract}
p53 plays a pivotal role in controlling the differentiation of mesenchymal stem cells (MSCs) by regulating genes involved in cell cycle and early steps of differentiation process. In the context of osteogenic differentiation of MSCs and bone homeostasis, the osteoprotegerin/receptor activator of NF-KB ligand/receptor activator of NF-KB (OPG/RANKL/RANK) axis is a critical signaling pathway. The absence or loss of function of p53 has been implicated in aberrant osteogenic differentiation of MSCs that results in higher bone formation versus erosion, leading to an unbalanced bone remodeling. Here, we show by microCT that mice with p53 deletion systemically or specifically in mesenchymal cells possess significantly higher bone density than their respective littermate controls. There is a negative correlation between p53 and OPG both in vivo by analysis of serum from $\mathrm{p} 53^{+/+}, \mathrm{p} 53^{+/-}$, and $\mathrm{p} 53^{-/-}$mice and in vitro by $\mathrm{p} 53$ knockdown and ChIP assay in MSCs. Notably, high expression of Opg or its combination with low level of p53 are prominent features in clinical cancer lesion of osteosarcoma and prostate cancer respectively, which correlate with poor survival. Intra-bone marrow injection of prostate cancer cells, together with androgen can suppress p53 expression and enhance local Opg expression, leading to an enhancement of bone density. Our results support the notion that MSCs, as osteoblast progenitor cells and one major component of bone microenvironment, represent a cellular source of OPG, whose amount is regulated by the p53 status. It also highlights a key role for the p53-OPG axis in regulating the cancer associated bone remodeling.
\end{abstract}

These authors contributed equally: Tania Velletri, Yin Huang, Yu Wang

\section{Edited by E. Baehrecke}

Supplementary information The online version of this article (https:// doi.org/10.1038/s41418-020-0590-4) contains supplementary material, which is available to authorized users.

\footnotetext{
Gerry Melino

gm614@mrc-tox.cam.ac.uk

$\triangle$ Yufang Shi

yufangshi@sibs.ac.cn

$\triangle$ Ying Wang

yingwang@sibs.ac.cn

1 Key Laboratory of Tissue Microenvironment and Tumor, Shanghai Institute of Nutrition and Health, Shanghai Institutes for Biological Sciences, University of Chinese Academy of Sciences, Chinese Academy of Sciences, Shanghai 200031, China

2 Department of Experimental Medicine, TOR, University of Rome Tor Vergata, Rome, Italy
}

\section{Introduction}

Bone remodeling is an exquisitely coordinated physiological process that guarantees a balance between bone formation and bone degradation to replace old or damaged

3 Affiliated Cancer Hospital \& Institute, Guangzhou Medical University, Guangzhou 510000, China

4 Biochemistry Laboratory, Istituto Dermopatico Immacolata (IDIIRCCS), 00100 Rome, Italy

5 The First Affiliated Hospital of Soochow University and State Key Laboratory of Radiation Medicine and Protection, Institutes for Translational Medicine, Soochow University, 199 Renai Road, Suzhou 215123 Jiangsu, China

6 Medical Research Council, Toxicology Unit, University of Cambridge, Cambridge CB2 1QP, UK

7 Present address: Department of Experimental Oncology, Department of Experimental Oncology, IEO, European Institute of Oncology, IEO, IRCCS, 20139 Milan, Italy 
bone. This process is orchestrated by cellular and molecular mechanisms occurring in osteoblasts, cells generating bone, and osteoclasts, cells degrading bone. To ensure a balanced remodeling, it is necessary that osteoblasts and osteoclasts generate and resorb the same amount of bone, phenomena indicated as "coupling" $[1,2]$.

This process is driven by bone morphogenetic proteins that after binding to their specific receptors activate runtrelated transcription factor 2 (RUNX2), a master gene in regulating the complete differentiation of mesenchymal stem cells (MSCs) toward osteoblasts. Another important pathway regulating osteogenic differentiation of MSCs is the WNT-Frizzled- $\beta$-catenin pathway [3]. The WNT pathway can be inhibited by distinct molecules such as Dickkopf-related protein 1 secreted by various cell types in normal tissues and cytokines-activated malignant cells which can impair osteoblasts functionality [4]. Osteoclasts arise from hematopoietic stem cells that firstly differentiate toward the monocyte/macrophage lineage through the macrophage-colony stimulating factor (M-CSF). Next step involves the activation of the receptor activator of nuclear factor- $\mathrm{KB}$ ligand (RANKL). The binding of RANKL to RANK will start different signal transduction pathways by tumor necrosis factor (TNF) receptor-associated factor 6, nuclear factor- $\mathrm{\kappa B}(\mathrm{NF}-\kappa b)$, and $\mathrm{c}-\mathrm{Jun}-\mathrm{N}$ terminal kinase (JNK/C Jun/fos).

Of note, a common and close niche in the bone marrow has been proposed for both osteoblasts and osteoclasts meaning that they can strictly influence and regulate each other by direct cell contact or by other mechanisms $[5,6]$. The OPG/RANKL/RANK axis has been found to be crucial for bone remodeling $[1,7]$. OPG is a member of the TNF receptor family which acts as a soluble decoy receptor to inhibit osteoclastogenesis [8]. It can suppress the activity and survival of osteoclasts through sequestering RANKL $[9,10]$ from binding to RANK on the surface of osteoclast cells. In addition, OPG was recently found to be highly expressed in advanced prostate cancer patients with bone metastasis, confirming a role in tumor progression [11]. Deletion of OPG results in a severe osteoporosis and vascular calcification due to enhanced bone resorption [12]. Oppositely, osteoporotic mice (op/op) reveal a loss of progenitor cells for both osteoclasts and macrophages with higher bone density [13].

In this context, the transcription factor p53, a well-known regulator of DNA damage response and cell death [14-20] plays a determinant role as a negative regulator of osteogenesis and osteoblast differentiation [21, 22]. Indeed, while p53 is a powerful regulator of cell death, a crucial mechanism for its role in cancer development [23-26], it has a basic effect on metabolism [27, 28] and other biologic processes [28, 29] including the regulation of MSCs $[30,31]$. It is evident that cancer cells can selectively silence p53 activities in cancer stromal cells, thereby molding the cancer stroma to facilitate cancer progression [32, 33]. Indeed, inactivation of p53 and retinoblastoma gene in bone marrow derived MSCs can promote the development of osteosarcoma-like cancer when transplanted in immunodeficient mice [34]. Despite recent advances, the functions and potential molecular regulations of p53 in MSC biology during cancer progression are not fully understood.

Here, we hypothesize that there are unexplored main factors potentially contributing to the osteosclerotic-like phenotype observed in $\mathrm{p} 53^{-1-}$ mice including: (i) $\mathrm{p} 53$ regulation of the molecular secretion profile of MSCs, (ii) correlation of $\mathrm{p} 53$ and the OPG/RANKL axis in MSCs, and (iii) $\mathrm{p} 53$ regulation of monocytes differentiation towards osteoclasts. By the selective deletion of p53 in mesenchymal cells, we show that p53 negatively regulates the expression of OPG in MSCs both in vitro and in vivo. More importantly, high level of $O P G$ is correlated with a poor prognostic in both prostate cancer and osteosarcoma. In a prostate cancer metastasis model, impaired p53 expression can promote $\mathrm{Opg}$ expression, and enhance bone density. Overall, we speculate that p53 constrains significantly the differentiation potential of osteoclast progenitor cells toward osteoclasts, and constructs the metastatic niche of prostate cancer through the regulation of OPG expression.

\section{Results}

\section{Loss of p53 impairs bone homeostasis and OPG/ RANKL ratio}

p53 inactivation induced by mutations occurs in more than half of all cancer patients including prostate cancer and osteosarcoma [32]. The progression of these cancers is always accompanied by aberrant bone remodeling [35]. Considering the tight interplay between p53 and the process of bone homeostasis [36], we decided to investigate the link between p53 and bone biology in vivo. To do so, we analyzed both femurs and tibias harvested from mice with different p53 status by micro computed tomography (microCT) (Fig. 1a). As previously demonstrated [21], quantitative analysis revealed a significant increase in bone density in $\mathrm{p} 53^{-/-}$mice as compared to $\mathrm{p} 53^{+/+}$and $\mathrm{p} 53^{+/-}$ control littermates (Fig. 1c). Notably, a significant increase in trabecular thickness was found in $\mathrm{p} 53^{--}$mice compared to $\mathrm{p}^{+/+}$controls (Fig. 1d), whereas no significant difference was observed in cortical bone (Fig. 1e). Histologically, haematoxylin and eosin staining performed on decalcified bone sections of $\mathrm{p} 53^{+/+}, \mathrm{p} 53^{+/-}$, and $\mathrm{p} 53^{-/-}$mice verified the results of the microCT (Fig. 1b). Because the OPG/ RANKL axis plays a key role in bone remodeling and their 

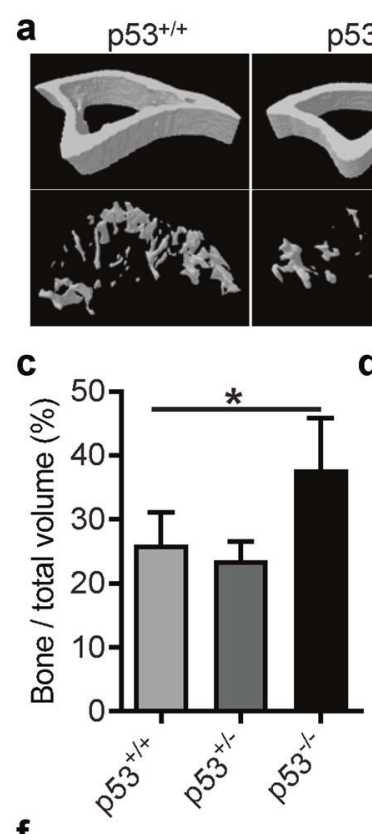

f

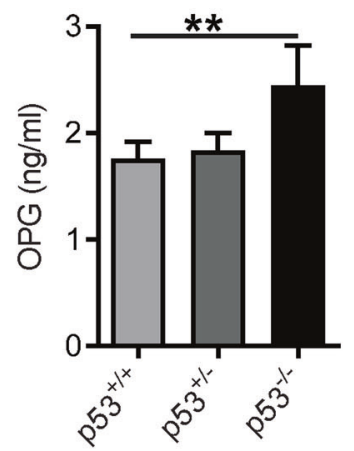

i

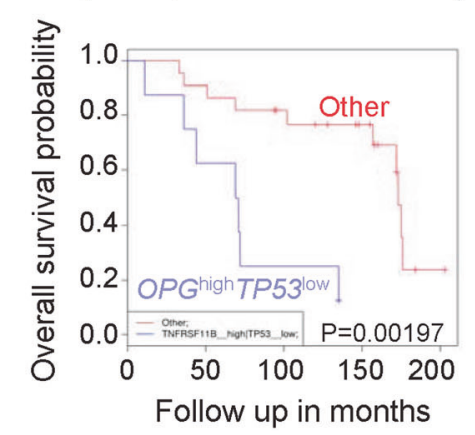

Fig. 1 Loss of p53 impairs bone homeostasis and the normal OPG/ RANKL ratio. Representative images of microCT (a) and $\mathrm{H} \& \mathrm{E}$ staining (b) of bone from $\mathrm{p} 53^{+/+}, \mathrm{p} 53^{+/-}$, and $\mathrm{p} 53^{-/-}$mice. Scale bar represents $100 \mu \mathrm{m}, n=5$. Quantification of bone volume relative to total volume (c), trabecular bone thickness $(\mathbf{d})$, and cortical bone thickness (e) from representative microCT scans in $\mathbf{a}, n=5$. Serum OPG (f) and RANKL (g) were measured in $\mathrm{p} 53^{-1-}(n=6), \mathrm{p} 53^{+/-}$

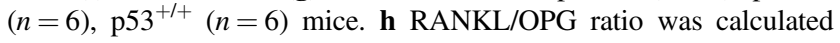

ratio is a measure of osteoclast activation [37], we aimed to investigate their interplay with the p53 status. Serum from $\mathrm{p} 53^{+/+}, \mathrm{p} 53^{+/-}$, and $\mathrm{p} 53^{-/-}$mice was collected and protein levels of OPG and RANKL were assessed by the enzyme linked immunosorbent assay (ELISA). We found a

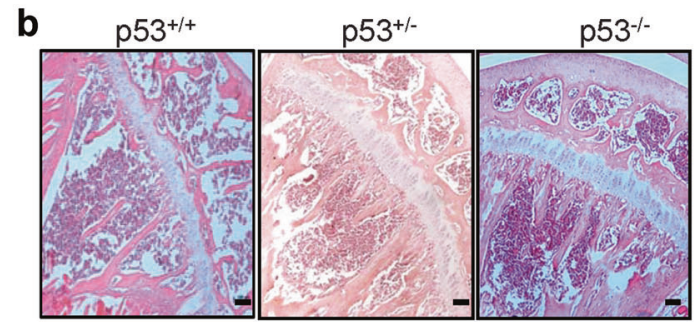

e
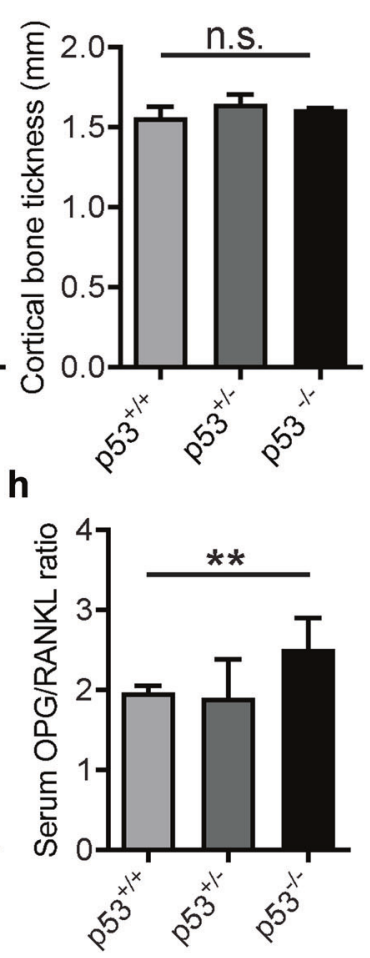

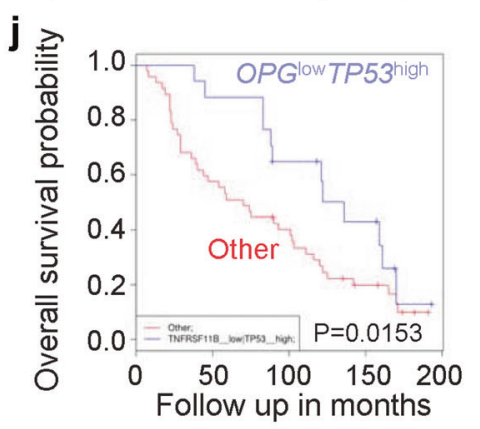

according the serum values of OPG and RANKL obtained in $\mathbf{f}$ and $\mathbf{g}$. $\mathbf{i}$, j Overall survival of prostate cancer patients was analyzed by Synergy2G. GSE16560 was selected. 30 samples from batch 6 (i) and 64 samples from batch $4(\mathbf{j})$ were shown as plots. $O P G^{\text {high }} T P 53^{\text {low }}$ or $O P G^{\text {low }} T P 53^{\text {high }}$ were shown as blue, and the others were shown as red. Data are presented as mean \pm SD. ${ }^{*} p<0.05$, $* * p<0.01$, n.s. not significant. All replicates are biological replicates.

significantly higher level of OPG in the serum of $\mathrm{p} 53^{-/-}$ mice compared to $\mathrm{p} 53^{+/+}$ones (Fig. 1f). On the other side, no significant difference was observed for the concentration of RANKL (Fig. 1g). Furthermore, a significant increase in the OPG/RANKL ratio was found in the serum of $\mathrm{p} 53^{-/-}$ 
mice, suggesting an impaired osteoclasts activity in the absence of p53 (Fig. 1h).

Assuming that the OPG/RANKL ratio is a measure of osteoclasts activation and that it has been negatively associated with the progression of bone degradation in an independent mechanism from inflammation [38], we injected RANKL subcutaneously over the femur of wild-type and $\mathrm{p} 53^{-1-}$ mice according to an established protocol [39] in order to evaluate whether: (i) it could affect OPG/ RANKL ratio, or (ii) alteration of the OPG/RANKL ratio could affect bone formation. Interestingly, we found a significant decrease of trabecular thickness and a slight decrease of bone/total volume in $\mathrm{p} 53^{-/-}$mice injected with RANKL compared to the control mice (Fig. S1a, b).

To reveal the role of p53 and OPG in cancer associated bone remodeling, we use Synergy2G (www.bioprofiling.de/ synergy2g) to explore their correlation in prostate cancer patients $[40,41]$. In GSE16560, $O P G^{\text {high }} T P 53^{\text {low }}$ patients showed poor prognosis while $O P G^{\text {low }} T P 53^{\text {high }}$ patients showed better overall survival, indicating a potential relationship between p53 and OPG in determination of the progression of prostate cancer (Fig. 1i, j). Given that the metastatic lesion in prostate cancers are prone to be osteoblastic instead of osteolytic, the correlation between TP53/ $O P G$ expression and overall survival could point to the possibility that low expression of TP53 and high expression of $O P G$ in prostate cancer would induce the enhancement of bone density and set up a metastatic niche. Also, $O P G$ can serve as a potential prognostic biomarker in Ewing sarcoma. Kaplan-Meier analysis showed that low level of $O P G$ is associated with higher event-free survival (Fig. S1c, d) and overall survival (Fig. S1e) in patients with mixed Ewing sarcoma and tumor Ewing sarcoma, respectively. In addition, $O P G$ expression has an opposite prognostic value in patients with mixed Ewing sarcoma, however, the analysis fails to reach statistical significance (Fig. S1f). Collectively, all these data suggest that p53 could affect bone remodeling indirectly and contributing to higher bone intake, and thus abnormal p53 expression in cancer patients may regulate pathological bone remodeling and tumor progression through OPG.

\section{p53 deficiency alters the osteogenic differentiation of MSCs}

MSCs represent a population of multipotent progenitor cells that can generate various mesenchymal lineages under specific in vitro culture condition [42, 43]. Importantly, MSCs resident in the bone marrow can assist the regeneration of mesenchymal tissues such as adipose, cartilage, and bone [44]. Therefore, according to the significantly higher bone density and trabecular bone thickness detected in p53 deficient mice, we thought to further investigate the role of p53 in bone homeostasis during osteogenic differentiation of mouse derived MSCs. To do so, we generated $\mathrm{p} 53^{\mathrm{f} /}$ ${ }^{\mathrm{f}}$ Dermo1-cre mice that induce a specific deletion of $\mathrm{p} 53$ in MSCs, a cell source for generation of osteoblasts. Similar to that in p53 deficiency mice, p53/f Dermo1-cre mice exhibited much higher bone density compared to that of littermate controls (Fig. 2a, b). To investigate whether p53 directly regulated MSC differentiation, we isolated MSCs from bone marrow of $\mathrm{p}^{+1 /+}$ and $\mathrm{p} 53^{-/-}$mice as previously described [45]. p53 expression was shown to be undetectable in $\mathrm{p} 53^{-1-}$ MSCs by real-time $\mathrm{qPCR}$ and western blotting analysis matching with the mouse genotype (Fig. S2a, b). Both $\mathrm{p} 53^{+/+}$and $\mathrm{p} 53^{-/-}$MSCs showed a common phenotype of MSCs: CD $44^{+}, \mathrm{Sca}-1^{+}, \mathrm{CD} 140 \mathrm{a}^{+}, \mathrm{CD} 13^{+}$, MHC $\mathrm{II}^{-}, \mathrm{CD} 11 \mathrm{c}^{-}, \mathrm{CD}_{11 \mathrm{~b}^{-}}, \mathrm{CD}^{-} 6^{-}$, and $\mathrm{CD} 45^{-}$ (Fig. S2c), indicating that p53 deficiency did not affect MSC phenotypic markers. To investigate whether $\mathrm{p} 53$ regulates osteogenesis of MSCs, we cultured $\mathrm{p} 53^{+/+}$and $\mathrm{p} 53^{-/-}$ MSCs in the appropriate osteogenic differentiation medium [46]. Alizarin red staining performed at different time points of the osteogenic differentiation of MSCs revealed that p53 deficient cells exhibited an accelerated differentiation compared to wild-type MSCs (Fig. 2c). Real-time qPCR for osteogenic transcription factors involved in the early phases of osteogenic differentiation such as Osterix (Osx) and Runx2 [47] revealed their upregulation existed in $\mathrm{p} 53^{-1-}$ MSCs compared to $\mathrm{p} 53^{+/+}$even without the osteogenic differentiation (Fig. 2d).

\section{OPG production is increased in p53 deficient MSCs}

OPG is a member of the tumor necrosis factor receptor family that functions as soluble decoy receptor and inhibitor for RANKL via abrogating its interaction with RANK expressed on the surface of progenitor and mature osteoclasts [48]. However, it has not been reported whether bone marrow derived MSCs as osteoblasts precursors could represent a source for the production of OPG. For this reason, we analyzed OPG expression by real-time qPCR and ELISA in $\mathrm{p} 53^{+/+}$and $\mathrm{p} 53^{-/-}$MSCs. Compared to $\mathrm{p} 53^{+/+}$MSCs, $\mathrm{p} 53^{-/-}$MSCs exhibited higher expression and production of OPG at both mRNA and protein levels (Fig. 3a, b). These results indicate that $\mathrm{p} 53$ deficiency affected OPG production in MSCs, however, the changes detected in these MSCs could occur sequentially following a developmental effect of p53 loss on MSCs. To bypass this issue and to further corroborate the direct role of p53 in MSCs, we used short hairpin RNA to knock down p53 in MSCs. A successful knockdown of p53 in MSCs was demonstrated at mRNA and protein levels (Fig. 3c, d). Interestingly, we found that Opg mRNA and protein significantly increased in p53 knockdown MSCs (Fig. 3e, f), confirming that MSCs can act as a source for the production of OPG and $\mathrm{p} 53$ has a negative effect on OPG expression in MSCs. 
Fig. 2 p53 deficiency alters the osteogenic differentiation of MSCs. a Representative microCT images from $\mathrm{p} 53^{\mathrm{f} / \mathrm{f}}$ $(n=4)$ or $\mathrm{p} 53^{\mathrm{f} / \mathrm{f}}$ Dermo1-cre $(n=3)$ mice. b Quantification of bone volume relative to total volume (left) and bone surface density (right) from representative microCT scans in a. c $\mathrm{p} 53^{+/+}$and $\mathrm{p} 53^{-/-}$MSCs were cultured in osteogenic differentiation medium for indicated days and stained with Alizarin Red S. d p53 $3^{+/+}$and $\mathrm{p} 53^{-1-}$ MSCs were analyzed for Osterix, Runx 2 mRNA to verify their basal level expression. Data are presented as mean $\pm \mathrm{SD}$ (b) or mean $\pm \operatorname{SEM}(\mathbf{d}) .{ }^{*} p<0.05$, $* * p<0.01, * * * p<0.001$. All experiments were repeated at least twice (biological replicas) with identical or comparable results. a

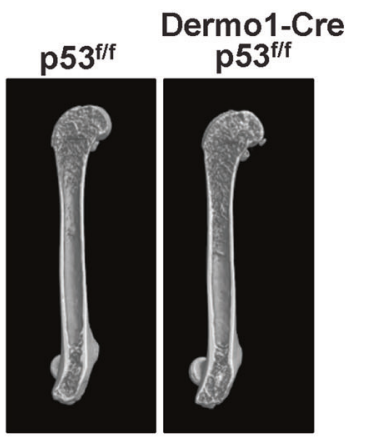

\section{b}
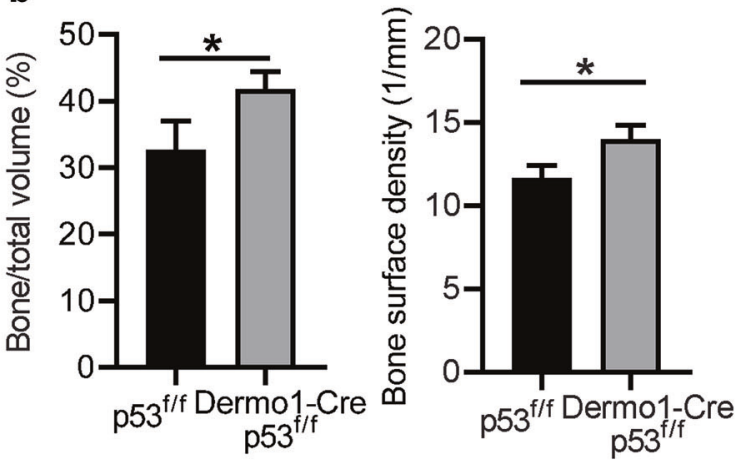

C

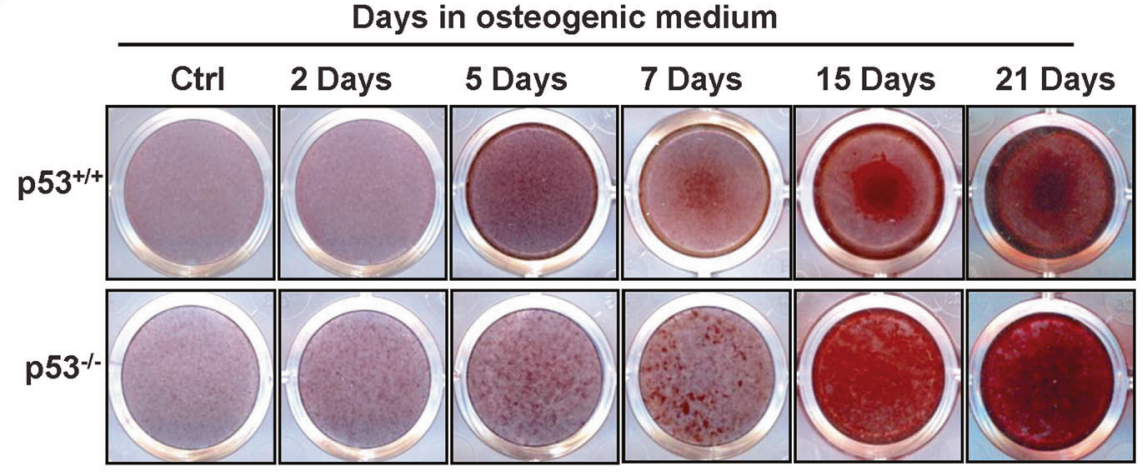

d

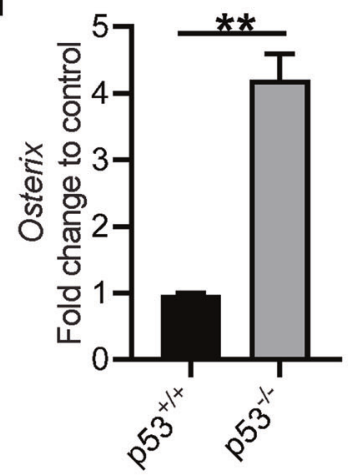

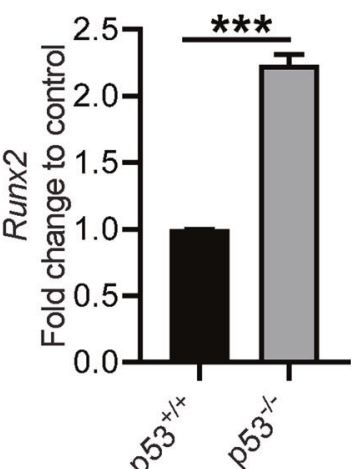

To further investigate the negative effect of p53 on $\mathrm{Opg}$ expression in MSCs, $\mathrm{p} 53^{+/+}$MSCs were treated with the inhibitor Nutlin-3 to block the interaction between p53 and murine double minute 2 . The upregulation of p53 mediated by Nutlin-3 treatment (Fig. 3g) repressed the expression of Opg in wild-type MSCs (Fig. 3h), confirming a negative regulation of OPG by p53 in MSCs. In addition, when p53 was upregulated following treatment with cisplatin to induce DNA damage (Fig. S3a-c), we observed a decrease in the Opg expression in p53 $3^{+/+}$MSCs (Fig. S3d). Next, we assessed whether p53 could also regulate the expression of OPG in human MSCs. To this end, we successfully knocked down p53 with shRNA in human umbilical cord derived MSCs (hUC-MSCs) as shown in Fig. S3e, f. Similar to what we observed in mouse derived MSCs, we found that the knockdown of $\mathrm{p} 53$ in hUC-MSCs promoted a significant increase of $O P G$ expression (Fig. S3g). To test whether p53 represses the transcription of Opg through binding its promoter, we performed a chromatin immunoprecipitation assay (ChIP). As shown in Fig. 3i, p53 significantly associates with the Opg promoter in wild-type MSCs as compared to p53 deficient MSCs, suggesting that p53 represses the transcription of $O p g$ by binding to the Opg promoter.

\section{Osteoclasts derived from $\mathrm{p} 53^{-1-}$ monocytes exhibit impaired functionality}

Bone remodeling is a process balanced through bone formation and bone resorption, with the latter mediated by mature and functional osteoclasts [2]. To extend the phenomena to the more general regulation of bone physiology, we assessed whether the absence of p53 could also affect osteoclast differentiation [49]. To this purpose, we isolated 
a

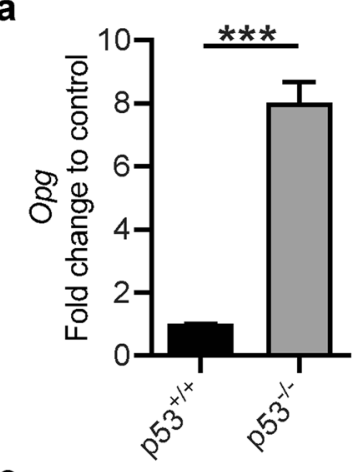

e
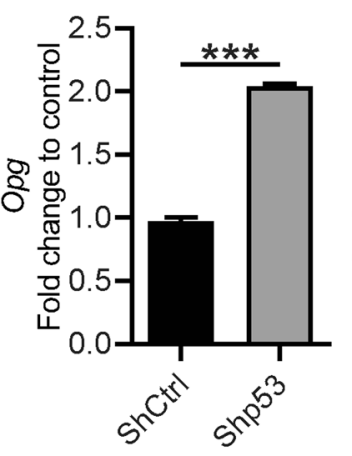

i

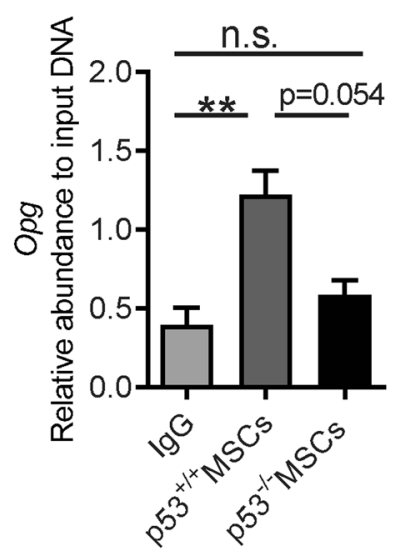

Fig. 3 OPG production is increased in $p 53$ deficient MSCs. a Quantification of Opg mRNA expression in $\mathrm{p} 53^{+/+}$and $\mathrm{p} 53^{-/-}$ MSCs by real-time qPCR. b Quantification of OPG protein levels in the culture supernatant from $\mathrm{p} 53^{+/+}$or $\mathrm{p} 53^{-/-}$MSCs. c, d p53 MSCs were transfected with p53 short hairpin RNA lentiviral particles (shp53) or control shRNA (shCtrl). After infection, cells were selected through puromycin selection $(3 \mu \mathrm{g} / \mathrm{ml})$ for 3 days. MSCs were analyzed for both p53 mRNA (c) and protein (d), to verify the efficiency of knockdown. e Quantification of Opg mRNA expression in shp53 and shCtrl MSCs. f Quantification of OPG protein levels in culture

monocytes from bone marrow of $\mathrm{p} 53^{+/+}$and $\mathrm{p} 53^{-/-}$mice as previously described [50]. We found an increase in the percentage of $\mathrm{Ly} 6 \mathrm{C}^{+} \mathrm{CD} 11 \mathrm{~b}^{+}$cells in $\mathrm{p} 53^{-1-}$ mice compared to control mice (Fig. S4a, b). Then, we differentiated the isolated monocytes towards osteoclasts using conditional medium culture as previously reported [6, 50]. The differentiation of osteoclasts was investigated by tartrate resistant acid phosphatase (TRAP) staining and by
C

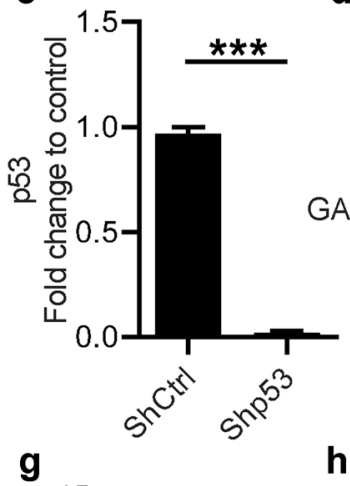

d

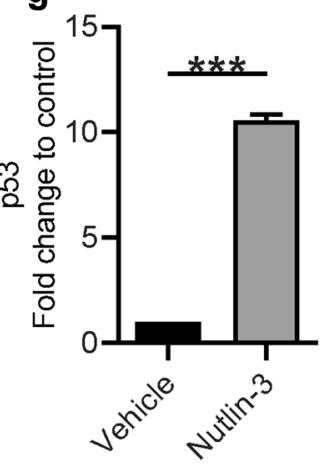

h

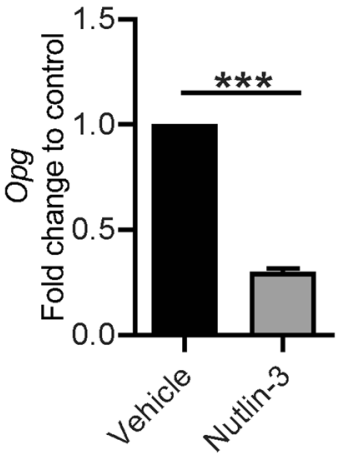

supernatants from shp53 and shCtrl MSCs. $\mathbf{g}$, h Mouse bone marrow derived $\mathrm{p}^{+/ /+}$MSCs were treated with nutlin-3 $(5 \mu \mathrm{M})$ or DMSO (vehicle control) for $24 \mathrm{~h}$ and then lysed and analyzed for p53 (g) and Opg (h) mRNA expression by qPCR. i Chromatin immunoprecipitation (ChIP) analysis was performed using anti-p53 antibodies or IgG for immunoprecipitation and subsequently analyzed with $O p g$ promoter specific PCR. Data are presented as mean \pm SEM. $* * p<0.01$, $* * * p<0.001$. n.s. not significant. These results are representatives of three independent experiments with similar results.

real-time qPCR for specific genes expressed in mature osteoclasts. TRAP staining revealed higher percentage osteoclasts formation in monocytes derived from $\mathrm{p} 53^{+/+}$ mice compared to that from $\mathrm{p} 53^{-1-}$ mice (Fig. $4 \mathrm{a}-\mathrm{c}$ ). Along the osteoclast differentiation process, pre-osteoclasts fuse each other into mature multinucleated cells that are recognized to be active through the expression of key osteoclasts markers, such as: Trap and $\alpha V \beta 3$ integrin chains 
a

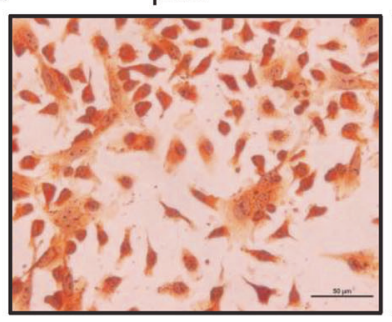

b

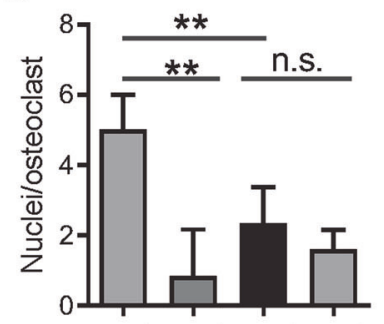

Genotype $\mathrm{p} 53^{+/+} \mathrm{p} 53^{+/+} \mathrm{p} 53^{-/-} \mathrm{p} 53^{-/-}$ OPG

Fig. 4 Osteoclasts derived from $\mathrm{p53}^{-1-}$ monocytes exhibit impaired functionality. a Representative images of osteoclast stained by T2RAP (red) after treatment for 7 days in specific medium plus $25 \mathrm{ng}$ / $\mathrm{ml} \mathrm{M-CSF}, 50 \mathrm{ng} / \mathrm{ml}$ RANKL, with or without OPG (50 ng/ml). Scale bar represents $50 \mu \mathrm{m}$. b, c Quantification of nuclei per osteoclast and

( $\beta 3$ integrin, Itgb3) [51]. We observed a significant reduction of mRNA expression of Trap enzyme as well as Itgb3 in the absence of p53 (Fig. 4d, e). These results indicated that monocytes derived from $\mathrm{p} 53^{-/-}$mice was impaired in achieving a complete osteoclast differentiation. Moreover, in order to investigate whether in a p53 null landscape the higher expression of $\mathrm{Opg}$ from MSCs could affect osteoclast maturation, we also implemented OPG protein in the conditional medium along with RANKL and M-CSF in the cultures of monocytes as previously mentioned. In these conditions, wild-type monocytes treated with OPG were less TRAP $^{+}$(Fig. 4a-c) and had a significant reduction in Trap, Itgb3 mRNA expression (Fig. 4d, e). Taking together, these data indicate that OPG can function as inhibitor of RANKL and induce a decreased differentiation capability in monocytes derived from wild-type mice versus osteoclasts but has less impact in the p53 null conditions.

\section{Regulation of the p53/0PG axis by androgen promotes bone remodeling in prostate cancer mice}

Given that the negative correlation between p53 and OPG is related to prognostic of prostate cancer, we further investigated the role of the $\mathrm{p} 53 / \mathrm{OPG}$ axis in preparing the bone metastatic niche during prostate cancer progression. We questioned if the prominent hormone acting on prostate cancer would affect p53 status and the bone homeostasis. As some prostate cancer cells acquired the ability to make
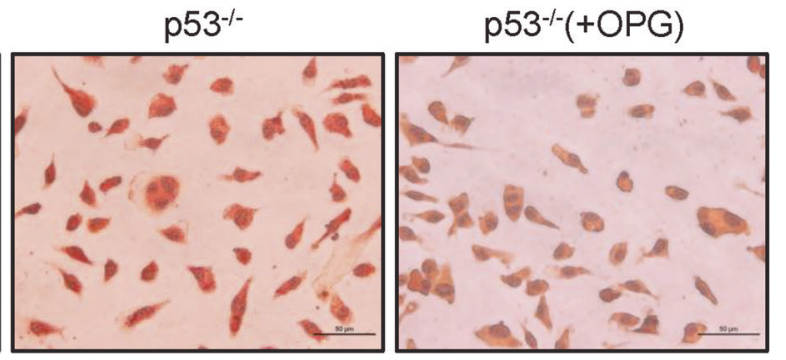

d
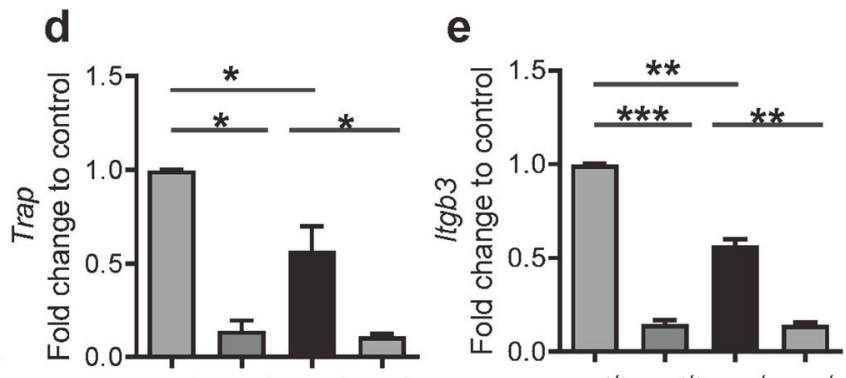

Genotype $p 53^{+/+} \mathrm{p} 53^{+/+} \mathrm{p} 53^{-/-} \mathrm{p} 53^{-/-}$

$\mathrm{OPG}$ - + - +

TRAP $^{+}$osteoclasts per field as shown in a. Quantification for Trap (d) and Itgb3 (e) mRNA expression of experiment shown in a. Data are shown as mean $\pm \mathrm{SD}$. $* p<0.05$, $* * p<0.01$, ***p ${ }^{*}<0.001$, n.s. not significant. The experiments were repeated at least twice (biological replicates) with similar results.

testosterone [52], to this end, we firstly used ELISA to assay the testosterone production by different prostate cancer cell lines, including DU145, LNCaP, and PC3 (Fig. 5a). Among them, a comparable level was demonstrated. To reveal the effect of androgen on p53 status, dihydrotestosterone (DHT) was added to hUC-MSCs treated with hydrogen peroxide (Fig. 5b). As expected, p53 was induced with the addition of hydrogen peroxide $\left(\mathrm{H}_{2} \mathrm{O}_{2}\right)$ and significantly suppressed in the presence of DHT. Thus, enriched androgen is one of the reasons to induce the loss of activity of p53 in MSCs. We further constructed a bone metastatic model of prostate cancer by intra-bone injection of $22 \mathrm{Rv} 1$ cells, a prostate cancer cell line with less androgen production. During this process, $22 \mathrm{Rv} 1$ cells were intra-bone injected to the right femur, with s.c administration of corn oil or testosterone three times per week for 8 weeks (Fig. 5c). Right femur and left femur were then analyzed by microCT. As demonstrated, the percentage of bone volume, bone surface density, and trabecular number in the right femur (with prostate cancer cell injection) were much higher in testosterone-injected mice than those of corn oil injected control mice (Fig. 5d-g). By employment of immunostaining, we found that in contrast to control group, the right femur in testosterone-injected mice showed lower level of p53 and higher level of OPG (Fig. 5h). Taken together, these results demonstrate that prostate cancer cells modulate the p53/OPG axis in MSCs and their osteogenesis via androgen, and build up the bone metastatic niche. 


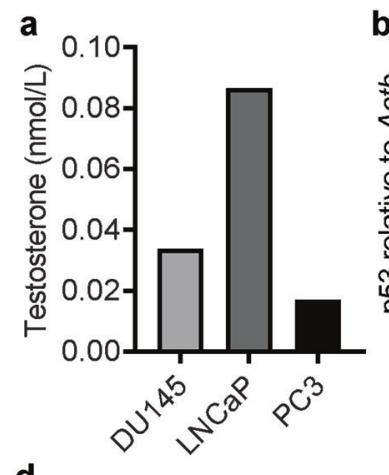

d

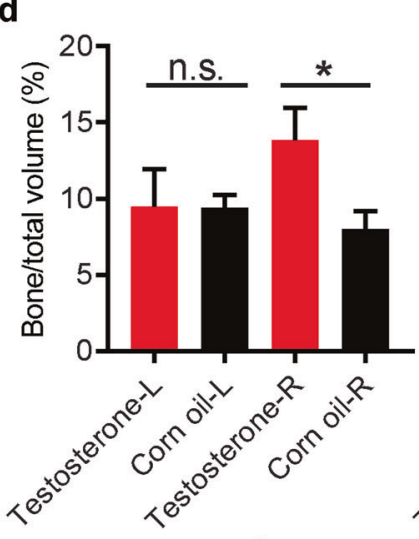

b 0.04

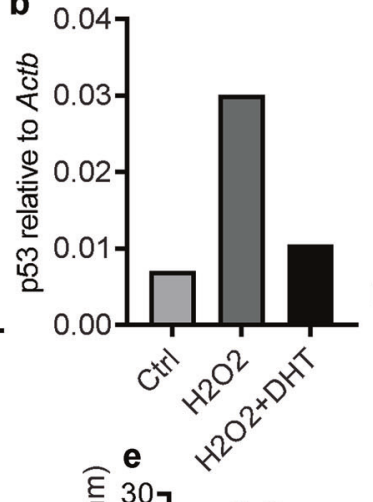

C

Corn oil or testosterone, s.c.

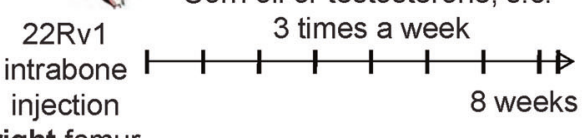

right femur
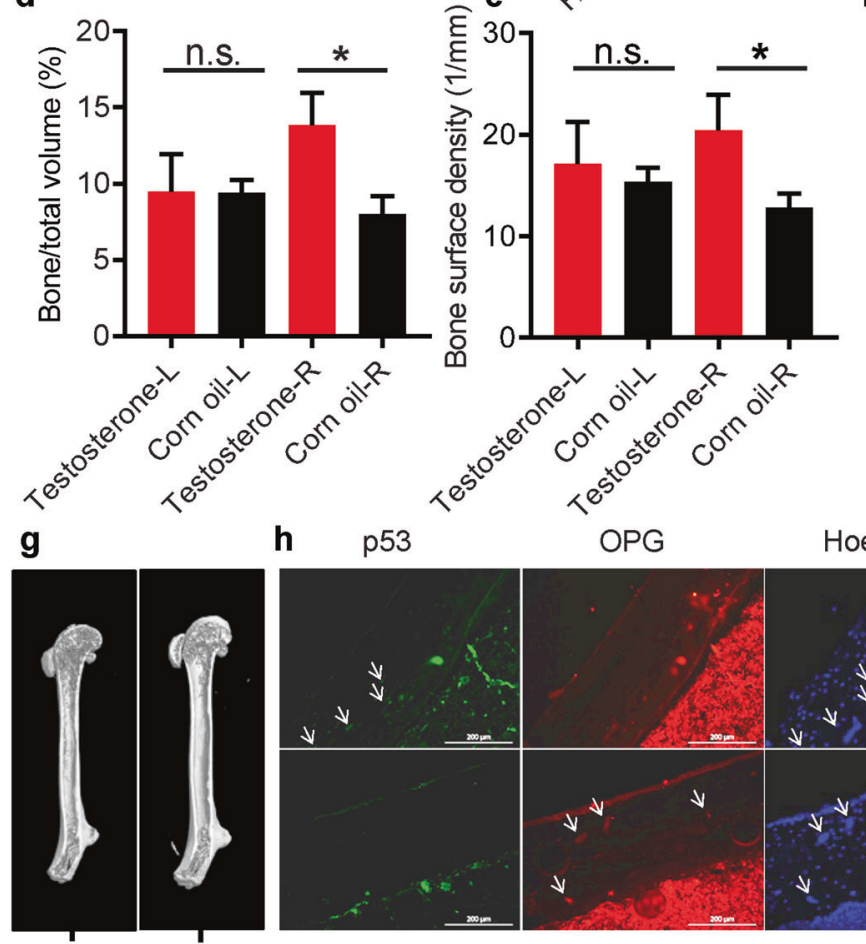

f

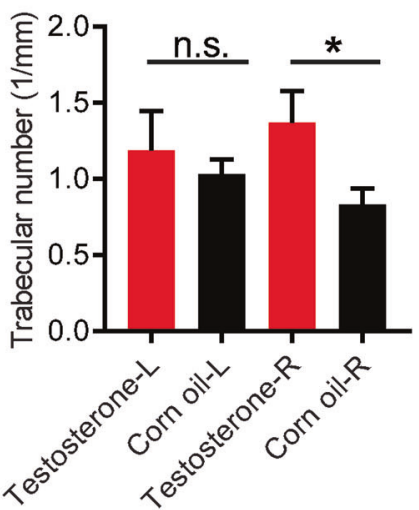

Merged

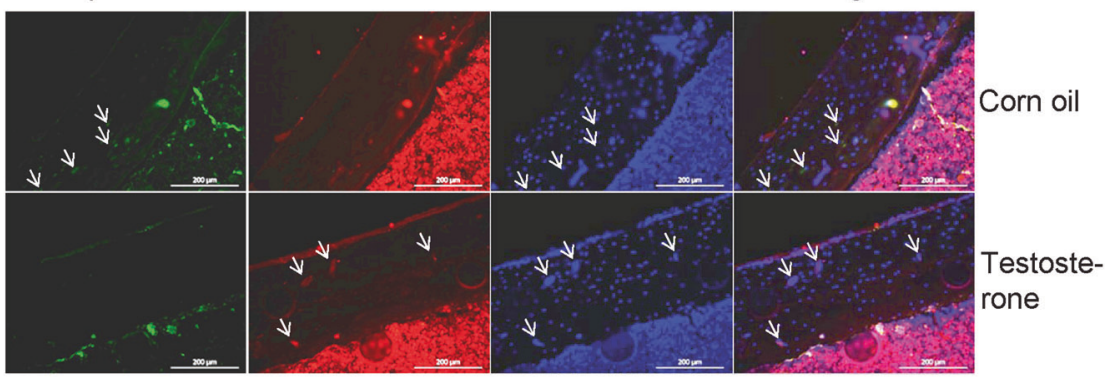

$$
\begin{aligned}
& \text { restoste- } \\
& \text { rone }
\end{aligned}
$$

Fig. 5 Regulation on the p53/OPG axis by androgen promotes bone remodeling in prostate cancer. a Testosterone concentrations in the culture supernatant from prostate cancer cell lines (DU145, LNCaP, and PC3) were analyzed by ELISA. b MSCs were treated with hydrogen peroxide $(2 \mathrm{mM})$ alone or combined with dihydrotestosterone (DHT, $100 \mathrm{nM}$ ) for $6 \mathrm{~h}$. p53 mRNA level was then analyzed by qPCR. c-f Human prostate cancer cell line 22Rv1 cells were intra-bone injected to the right femur of nude mice, with s.c administration of corn oil or testosterone $(200 \mu \mathrm{g} /$ mouse) three times per week for 8 weeks. c Schematic diagram of the tumorigenesis

\section{Discussion}

Our findings revealed a strong association among p53 deficiency, high levels of OPG, and more bone formation (Fig. 6). Following the original hypothesis that osteoblasts and stromal cells could regulate osteoclasts formation, activity, and bone resorption [53, 54], OPG was reported by several groups to protect the bone from excessive bone model. Quantification of Bone/total volume (d), bone surface density (e), and trabecular number (f) of the left and right femur by microCT $(n \geq 4)$. $\mathbf{g}$ Representative 3D reconstructing image of MicroCT of right femur with the administration of either testosterone or corn oil. h Immunohistostaining showed p53 and OPG levels in right femur. Top line was representative image of corn oil-treated control group and bottom line showed the testosterone-treated group. p53, OPG, and Hoechst were shown as green, red, and blue, respectively. Scale bar represents $200 \mu \mathrm{m}$. Data are shown as mean \pm SD. $* p<0.05$, n.s. not significant.

resorption and to inhibit osteoclasts activity by binding RANKL and hence avoiding its binding to RANK receptor [55]. In keeping with the crucial role of the OPG/ RANKL axis in bone biology, here we demonstrate that bone marrow derived MSCs are a source of OPG production. We found that p53 deficiency promoted a significant increment in the production of OPG at serum level and in bone marrow derived MSCs, indicating that the 


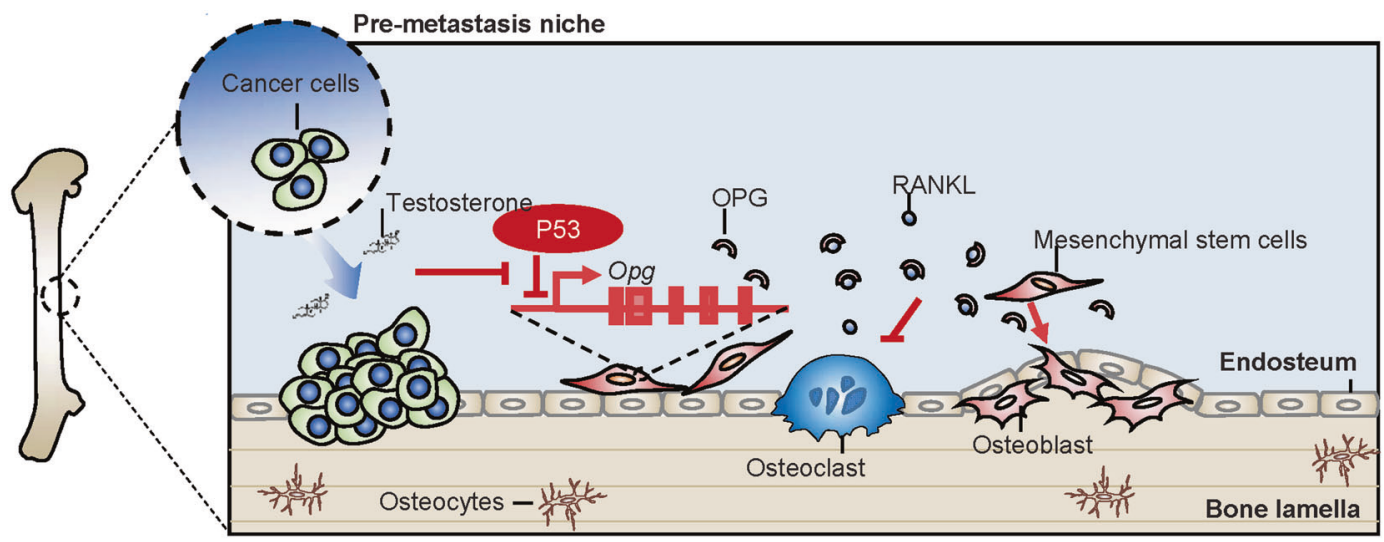

Fig. 6 Schematic representation of the proposed molecular mechanism by which p53 regulates bone remodeling. Enriched testosterone produced by prostate cancer cells can suppress p53 expression in MSCs. These MSCs with p53 deficiency exhibit more potential to generate osteoblasts and produce OPG. The enhanced OPG production can block the RANKL-RANK signaling in osteoclasts and results in an impairment of bone resorption. Such concerted action modulated by 553 regulates the bone remodeling and constructs the bone metastatic niche of prostate cancer. OPG osteoprotegerin, RANKL receptor activator of nuclear factor $\kappa \mathrm{B}$ ligand, RANK receptor activator of nuclear factor- $\mathrm{\kappa B}$.

production of OPG from MSCs can be modulated by p53 status.

Of note, we observed a significant increase in bone density and trabecular bone thickness, but not in cortical bone in p53 null mice. This can be explained by the different anatomic location and composition of the trabeculae compared to the cortical bone. Indeed in the trabecular bone, the trabeculae are interspersed in the bone marrow that represent the bone remodeling compartment containing bone marrow progenitor cells and is invaded by blood vessels which replace hematopoietic stem cells precursors for osteoclasts [2]. On the other hand, in the cortical bone, the blood and blood elements are provided by the Haversian canals. The direct evidence that loss of p53 contributes to the development of an aberrant bone phenotype ask for new questions on the molecular mechanism by which p53 coordinates osteoblasts and osteoclasts differentiation from their respective precursor cells. It has been reported that p53 acted as a negative regulator of osteoblastogenesis through repressing the expression of Osterix, a transcription factor involved in the early phase of osteogenic differentiation of osteoblast precursor cells [21]. Our findings reinforce the role of p53 in the regulation of osteoblast differentiation by adding a layer of complexity. First, we showed that p53 negatively regulated the expression of Opg in MSCs by binding to its promoter. Previous studies have demonstrated that p53 can suppress the expression of certain genes directly or indirectly. In the context of p53 levels, cofactors or specific response element sequences used, p53 was found to repress the expression of IL-6, VEGF-A, and Osterix at the transcriptional level [21, 56-58]. The indirect repressing activity of p53 on targeted genes could be mediated by other DNA-binding proteins and co-repressors such as the CAAT-binding factor [59]. Also, its indirect regulation can be exerted by interference with the assembly of the transcription-initiation complex, or recruitment of histone deacetylase which functions as repressors of transcription [60]. Therefore, further investigation focusing on elucidating the molecular mechanism of p53 binding on Opg promoter will provide critical information on the detailed regulation of Opg expression by p53. Second, we revealed that p53 negatively regulated osteoclast differentiation. In fact, monocytes

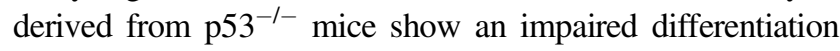
towards the osteoclast lineage. Moreover, secreted OPG did not have effect on the growth rate of MSCs itself (data not shown). Nevertheless, we show that the differentiation potential of $\mathrm{p} 53^{-1-}$ monocytes into osteoclasts is also significantly impaired when we supplement OPG to the conditional medium for osteoclasts differentiation.

Opg deficient mice exhibit severe osteoporosis as a result from increased osteoclast activity in bone resorption, along with higher concentration of RANKL in the serum compared to wild-type mice [61]. Interestingly, we found that RANKL injection in femur of wild-type and $\mathrm{p} 53^{-/-}$mice reduced bone density and trabecular thickness. We performed our analysis on mice $<15$-week-old to avoid the presence of tumor that frequently occurs in p53 null condition and with higher frequency in $\mathrm{p}^{+/-}$mice [62]. We do not exclude the possibility that along with age, MSCs as part of the tumor microenvironment could secrete a new panel of molecules that can further affect bone homeostasis and promote tumor development or be recruited to the site of tumor formation, especially considering the influence of oxidative stress, inflammation, and tumor formation. Indeed, we provide evidence that bone marrow derived MSCs are an important source of OPG, and p53 negatively regulates its expression in prostate cancer bone metastatic niche. We suggest a link between p53 functionality in MSCs through the OPG/RANKL pathway, and we underline the importance of MSCs in regulating bone formation 
through their functionality and immunomodulatory properties modulated by $\mathrm{p} 53$. This, in the context of bone microenvironment will provide new insights related to bone remodeling and physiology but also to determine mechanisms in charge of disruption of bone homeostasis and dissociated coupling in age and in bone tumor development.

\section{Materials and methods}

\section{Reagents}

The following antibodies were used in flow cytometry: phycoerythrin (PE)-conjugated anti-mouse CD44 (Biolegend, 103007), Sca-I (eBioscience, 12-5981-83), CD140a (Biolegend, 135906), CD13 (BD Pharmingen, 558745), MHC II (eBioscience, 12-5320-80), CD11b (eBioscience, 12-0112-83), CD11c (eBioscience, 12-0114-82), CD86 (eBioscience, 12-0862-82), and CD45 (eBioscience, 120451-82). Antibodies used for western blotting analysis were: anti-p53 (FL-393; sc-6243, Santa Cruz Biotechnology); GAPDH (14C10, 2118, Cell Signaling Technology). Antibody used for Chip was: p53 (FL-393; sc-6243, Santa Cruz Biotechnology), IgG (normal mouse IgG, sc2025, Santa Cruz Biotechnology). The reagents for cell treatment were: Nutlin-3 (Nutlin-3, Selleck Chemicals, Houston, TX, USA), Cisplatin (Sigma-Aldrich), RANKL (recombinant mouse RANKL, $50 \mathrm{ng} / \mathrm{ml}$, R\&D), M-CSF (recombinant mouse M-CSF, $25 \mathrm{ng} / \mathrm{ml}$, R\&D), and OPG (recombinant OPG, $50 \mathrm{ng} / \mathrm{ml}$, Sigma-Aldrich). RANKL for mouse injection (recombinant mouse RANKL, $2 \mathrm{mg} / \mathrm{kg} /$ day) was from R\&D Systems.

\section{Mice}

C57BL/6 and nude mice were purchased from the Shanghai Laboratory Animal Center of Chinese Academy of Sciences, Shanghai, China. $\mathrm{p} 53^{-1-}$ mice were from Animal Model Research Center of Nanjing University, Nanjing, China. Dermo1-Cre mice were purchased from The Jackson Laboratory (stock No. 008712). p53 $3^{\mathrm{f} / \mathrm{f}}$ mice were kindly gifted by Dr. Jun Qin, Shanghai Institute of Nutrition and Health. Mice were maintained under specific pathogen-free conditions in the animal facility of Institute of Health Sciences. All procedures were approved by the Institutional Animal Care and Use Committee of the Shanghai Institute of Nutrition and Health, Shanghai Institute for Biological Sciences of Chinese Academy of Sciences.

\section{Cells}

MSCs were derived from bone marrow of the tibia and femur of 6-8-week-old mice. The cells were cultured in
DMEM medium supplemented with $10 \%$ fetal bovine serum (FBS), $2 \mathrm{mM}$ glutamine, $100 \mathrm{U} / \mathrm{ml}$ penicillin, and $100 \mathrm{mg} / \mathrm{ml}$ streptomycin (all from Invitrogen, Carlsbad, CA). Non-adherent cells were discarded after $24 \mathrm{~h}$, and adherent cells were maintained with medium replenished every 3 days. At confluence, cells were harvested and seeded into 96-well plates by limited dilution. Individual clones were picked and expanded. MSCs were characterized by their expression of cell surface markers and their capability to differentiate into adipocytes and osteoblasts. Cells were used before the 15th passage. Human UC-MSCs were generated as previously described [63], and approved by the institutional biomedical research ethics committee of the Shanghai Institutes for Biological Sciences (Chinese Academy of Sciences). Primary monocytes were isolated from bone marrow flushed from the tibia of 7-8-week-old wild-type and $\mathrm{p} 53^{-1-}$ C57BL/6 mice and filtered through a $70 \mu \mathrm{m}$ cell-strainer. Cells were washed twice in fresh new medium and plated overnight in $\mathrm{MMEM}$ plus $10 \% \mathrm{FBS}$. Prostate cancer cell lines DU145, LNCaP, PC3, and 22Rv1 were provided by Dr. Jun Qin, Shanghai Institute of Nutrition and Health.

\section{Differentiation of MSCs}

For osteogenic differentiation, MSCs were cultured in osteogenic differentiation medium: DMEM supplemented with $10 \%$ FBS, $10 \mathrm{nM}$ dexamethasone, $10 \mathrm{mM} \beta$-glycerophosphate, and $100 \mathrm{mM}$ ascorbic acid. MSCs were seeded in 24well plate and maintained with osteogenic medium replenished every 3 days. These cultures were stained at appropriate time points with Alizarin Red S to identify calcium deposition, an indication of osteoblasts activity. All reagents were purchased from Sigma-Aldrich (St. Louis, MO).

\section{Osteoclast differentiation assay}

Bone marrow derived monocytes were isolated and then differentiated to osteoclasts as previously reported [6]. Briefly, $1 \times 10^{6}$ non-adherent cells derived from overnight culture of primary monocytes were plated in 24-well plate and supplemented with $50 \mathrm{ng} / \mathrm{ml}$ RANKL and $25 \mathrm{ng} / \mathrm{ml} \mathrm{M-CSF}$ the next day for 5 days with medium and cytokines replenishment every 2 days. An additional group for osteoclast differentiation was differentiated in the presence of $50 \mathrm{ng} / \mathrm{ml}$ OPG. Cells were fixed, TRAP was stained on day 6 using a leukocyte acid phosphatase kit (Sigma-Aldrich) and $\mathrm{TRAP}^{+}$multinucleated cells were considered as mature osteoclasts.

\section{Histological and microCT analysis}

Hind limb bones were excised from 15-week-old mice without detectable tumor, fixed with $10 \%$ neutral-buffered 
formalin. One limb from each mouse was collected for microCT analysis. The other hind limb was washed and decalcified in a solution of $10 \%$ EDTA for 2 weeks and then embedded in paraffin or Tissue-Tek ${ }^{\circ}$ O.C.T.T. ${ }^{\text {TM }}$ Compound (Sakura). Paraffin sections were performed and stained with hematoxylin and eosin (H\&E). For the Immunofluorescence staining, frozen sections were used and stained with antip53 and anti-OPG antibody following a standard protocol. Histological analysis was performed on sections of bones stained with H\&E using the Zeiss Axiovert 200 microscope, and the AxioVision software version 4.6.3 SP1. MicroCT images were reconstructed and analyzed by Shanghai Showbio Biotech, Inc.

\section{Chromatin immunoprecipitation}

A Total of $2 \times 10^{6}$ cells were used for immunoprecipitation. The MagnaChip system (Millipore) was used according to the manufacturer's instructions. Chromatin fragmentation was carried out by sonication of cell extract by using a Bioruptor sonicator with higher power for 30-s "on"/30-s "off" cycles for $20 \mathrm{~min}$. Immunoprecipitation was performed using $8 \mu \mathrm{g}$ anti-p53 antibody (Santa Cruz Biotechnology). Rabbit IgG were used as a negative control. DNA was purified and used as template for PCR reactions. We used primer flanking the $O p g$ promoter region in mouse and in human. Primers for ChIP analysis were designed as described in a previous study [64].

\section{Lentiviral infection}

Mouse and human p53 short hairpin RNA lentiviral particles were purchased from Santa Cruz Biotechnology (Santa Cruz, CA, USA). The lentiviral particles were added to the culture medium of MSCs and incubated for $24 \mathrm{~h}$ before puromycin screening. Cells were then selected through puromycin $(3 \mu \mathrm{g} / \mathrm{ml})$ for 3 days.

\section{Western blotting analysis}

Cells were harvested by scraping from the culture dish and washed twice with ice-cold phosphate buffered saline (PBS). Total protein was extracted from the cell pellet with RIPA lysis buffer (Upstate, Charlottesville, VA). Samples were incubated on ice for $30 \mathrm{~min}$ and then centrifuged at $12,000 \mathrm{~g}$ for $20 \mathrm{~min}$ at $4{ }^{\circ} \mathrm{C}$. Supernatants were collected and mixed with sodium dodecyl sulfate sample buffer, heated at $95{ }^{\circ} \mathrm{C}$ for $10 \mathrm{~min}$ and separated by polyacrylamide gel electrophoresis and electrical blotted to polyvinylidenedifluoride membranes (Whatman, Inc., Clifton, $\mathrm{NJ}$ ). Membrane was incubated for $1 \mathrm{~h}$ at room temperature in a blocking solution composed of 5\% skimmed milk powder dissolved in TBST $(0.05 \%$ Tween- $20,10 \mathrm{mM}$ Tris, $\mathrm{pH} 8.0$, and $140 \mathrm{mM} \mathrm{NaCl}$ ). After washing the membrane three times with TBST, proteins were revealed by mouse and rabbit antibodies against p53, or GAPDH by overnight incubation at $4{ }^{\circ} \mathrm{C}$. After three washes with TBST, membranes were incubated with anti-mouse or anti-rabbit secondary antibodies (Cell Signaling Technology, Inc.). The blots were then subjected to chemiluminescent detection according to the manufacturer's instructions.

\section{RNA extraction and qRT-PCR}

Total RNA was extracted with TRIzol reagent (Invitrogen, Carlsbad, CA) and reverse transcribed into cDNA using the Taqman reverse transcription kit (ABI, Carlsbad, CA). The levels of mRNA of interest genes were measured by realtime qPCR (7900 HT by Applied BioSystems, Foster City, CA, USA) using SYBR Green Master Mix (TaKara Biotech). Total amount of mRNA was normalized to endogenous Actb mRNA. Sequences of PCR primer pairs are listed in Table 1, in Supplementary Information.

\section{Flow cytometry analysis}

Cells were harvested and washed twice with PBS. The cell pellets were resuspended in staining buffer (PBS, 3\%FBS) at a density of $1 \times 10^{7}$ cells per milliliter. The cell suspension $(100 \mu \mathrm{l})$ was incubated for $30 \mathrm{~min}$ with conjugated antibodies. Cell were washed twice with the staining buffer, and analyzed by flow cytometry through a FACS Calibur flow cytometer (Becton Dickinson, San Jose, CA). Data were analyzed through FCS Express software. At least 20,000 events were collected for each analytical point.

\section{ELISA immunoassay}

Quantitative levels of murine OPG in the serum of $\mathrm{p} 53^{+/+}$, $\mathrm{p} 53^{+/-}$, and $\mathrm{p} 53^{-/-} \mathrm{C} 57 \mathrm{BL} / 6$ mice and in the conditioned medium of MSCs were determinate in triplicate by ELISA according to the manufacturer's protocol (Mouse OPG Quantikine ELISA kit immunoassay, R\&D). Quantitative levels of murine RANKL in serum of $\mathrm{p} 53^{+/+}, \mathrm{p} 53^{+/-}$, and $\mathrm{p} 53^{-1-}$ C57BL/6 were determined in triplicate by ELISA according to the manufacturer's protocol (Mouse RANKL Quantikine ELISA kit immunoassay, R\&D). Quantitative levels of human OPG in conditioned medium of hUC were determinate in triplicate by ELISA according to the manufacturer's protocol (Human Osteoprotegerin TFRSF11b ELISA kit, Sigma-Aldrich). Quantitative levels of testosterone were determined following the protocol of the Testosterone Parameter Assay Kit (R\&D system). 


\section{RANKL injection}

Mouse recombinant RANKL ( $2 \mathrm{mg} / \mathrm{kg} / \mathrm{day})$ or vehicle was injected subcutaneously over the femur, twice per day, for 5 days alternated by 2 days of rest. Mice were sacrificed on the 6th day, and the hind limbs were excised and processed for MicroCT analysis as already described.

\section{Prostate cancer model}

Human prostate cancer cell line 22Rv1 cells were intra-bone injected to the right femur, with s.c administration of corn oil or testosterone ( $200 \mu \mathrm{g} /$ mouse) three times per week for 8 weeks.

\section{Bioinformatic analysis}

Bioinformatic analysis was carried out by using the following website: R2: Genomics Analysis and Visualization Platform, https://r2.amc.nl. Adjustable settings: cutoff modus: scan; Sample Filter: NO.

Overall survival of prostate cancer patients was analyzed by Synergy $2 \mathrm{G}$ at the website www.bioprofiling.de/ synergy2g. GSE16560 was selected. A total of 30 samples from batch 6 and 64 samples from batch 4 were used.

\section{Statistical analysis}

The GraphPad Prism 5.0 software (GraphPad software, Inc., San Diego, CA) was used for the statistical analysis. Statistical significance was assessed by unpaired two-tailed Student's test and stated as follow: n.s., not significant; *p $<0.05 ; * * p<0.01 ; * * * p<0.001$.

Sample size was estimated empirically, according to the exploratory experiments and published literatures with similar methodology. Since no suggestive analysis was involved in this study, randomization, and blinding were not applied.

\footnotetext{
Acknowledgements We sincerely thank the generous help for providing $\mathrm{p} 53^{\mathrm{f} / \mathrm{f}}$ mice and prostate cancer cell lines from Dr. Jun Qin in Shanghai Institute of Nutrition and Health. This work is supported by grants from the National Key R\&D Program of China (2018YFA0107500), the Scientific Innovation Project of the Chinese Academy of Sciences (XDA16020403), the National Natural Science Foundation of China (81861138015, 31961133024, 31771641, 31601106,81930085 , and 81571612), the National Key R\&D Program of China (2018YFC1704300), the MAECI Italy-China Science and Technology Cooperation (\#PGR00961), the Youth Innovation Promotion Association research fund from the Chinese Academy of Sciences, the Ministry of Health Italy-China cooperation grant, and partially by the Medical Research Council, Associazione Italiana per la Ricerca contro il Cancro (AIRC, IG\#20473; 2018-2022), Fondazione Luigi Maria Monti IDI-IRCCS (RC to EC), AIRC (IG\#22206; 20192023) to EC. Work has been also supported by Regione Lazio through Lazio Innova Progetto Gruppo di Ricerca n 85-2017-14986 and by the Medical Research Council (to GM).
}

Author contributions TV, YH, and YuW developed the methodology, conducted the experiments, and analyzed data; QL, MH, NX, QY, XC, QC, PS, YG, and HY helped conduct experiments; EC, AM, and MA, performed bioinformatic analysis; TV, YH, and $\mathrm{YuW}$ prepared the original paper; QL, MH, EC, AM, MA, and HY made comments and suggestions; GM, YS, and YW led the project, and wrote the paper.

\section{Compliance with ethical standards}

Conflict of interest The authors declare that they have no conflict of interest.

Publisher's note Springer Nature remains neutral with regard to jurisdictional claims in published maps and institutional affiliations.

Open Access This article is licensed under a Creative Commons Attribution 4.0 International License, which permits use, sharing, adaptation, distribution and reproduction in any medium or format, as long as you give appropriate credit to the original author(s) and the source, provide a link to the Creative Commons license, and indicate if changes were made. The images or other third party material in this article are included in the article's Creative Commons license, unless indicated otherwise in a credit line to the material. If material is not included in the article's Creative Commons license and your intended use is not permitted by statutory regulation or exceeds the permitted use, you will need to obtain permission directly from the copyright holder. To view a copy of this license, visit http://creativecommons. org/licenses/by/4.0/.

\section{References}

1. Simonet WS, Lacey DL, Dunstan CR, Kelley M, Chang MS, Luthy R, et al. Osteoprotegerin: a novel secreted protein involved in the regulation of bone density. Cell. 1997;89:309-19.

2. Sims NA, Martin TJ. Coupling the activities of bone formation and resorption: a multitude of signals within the basic multicellular unit. Bonekey Rep. 2014;3:481.

3. Bodine PV, Komm BS. Wnt signaling and osteoblastogenesis. Rev Endocr Metab Disord. 2006;7:33-39.

4. Diarra D, Stolina M, Polzer K, Zwerina J, Ominsky MS, Dwyer $\mathrm{D}$, et al. Dickkopf-1 is a master regulator of joint remodeling. Nat Med. 2007;13:156-63.

5. Yin $\mathrm{T}, \mathrm{Li} \mathrm{L}$. The stem cell niches in bone. J Clin Investig. 2006;116:1195-201.

6. Helfrich MH, Thesingh CW, Mieremet RH, van Iperen-van Gent AS. Osteoclast generation from human fetal bone marrow in cocultures with murine fetal long bones. A model for in vitro study of human osteoclast formation and function. Cell Tissue Res. 1987;249:125-36.

7. Walia MK, Taylor S, Ho PWM, Martin TJ, Walkley CR. Tolerance to sustained activation of the cAMP/Creb pathway activity in osteoblastic cells is enabled by loss of p53. Cell Death Dis. 2018;9:844.

8. Kearns AE, Khosla S, Kostenuik PJ. Receptor activator of nuclear factor kappaB ligand and osteoprotegerin regulation of bone remodeling in health and disease. Endocr Rev. 2008;29:155-92.

9. Lacey DL, Tan HL, Lu J, Kaufman S, Van G, Qiu W, et al. Osteoprotegerin ligand modulates murine osteoclast survival in vitro and in vivo. Am J Pathol. 2000;157:435-48.

10. Udagawa N, Takahashi N, Yasuda H, Mizuno A, Itoh K, Ueno Y, et al. Osteoprotegerin produced by osteoblasts is an important regulator in osteoclast development and function. Endocrinology. 2000;141:3478-84. 
11. Brown JM, Vessella RL, Kostenuik PJ, Dunstan CR, Lange PH, Corey E. Serum osteoprotegerin levels are increased in patients with advanced prostate cancer. Clin Cancer Res. 2001;7:2977-83.

12. Bucay N, Sarosi I, Dunstan CR, Morony S, Tarpley J, Capparelli $\mathrm{C}$, et al. osteoprotegerin-deficient mice develop early onset osteoporosis and arterial calcification. Genes Dev. 1998;12: 1260-8.

13. Begg SK, Radley JM, Pollard JW, Chisholm OT, Stanley ER, Bertoncello I. Delayed hematopoietic development in osteopetrotic (op/op) mice. J Exp Med. 1993;177:237-42.

14. Aubrey BJ, Kelly GL, Janic A, Herold MJ, Strasser A. How does p53 induce apoptosis and how does this relate to p53-mediated tumour suppression? Cell Death Differ. 2018;25:104-13.

15. Baugh EH, Ke H, Levine AJ, Bonneau RA, Chan CS. Why are there hotspot mutations in the TP53 gene in human cancers? Cell Death Differ. 2018;25:154-60.

16. Sullivan KD, Galbraith MD. Mechanisms of transcriptional regulation by p53. Cell Death Differ. 2018;25:133-43.

17. Engeland K. Cell cycle arrest through indirect transcriptional repression by p53: I have a DREAM. Cell Death Differ. 2018;25:114-32.

18. Kaiser AM, Attardi LD. Deconstructing networks of p53mediated tumor suppression in vivo. Cell Death Differ. 2018;25: 93-103.

19. Kim MP, Lozano G. Mutant p53 partners in crime. Cell Death Differ. 2018;25:161-8.

20. Wu D, Prives C. Relevance of the p53-MDM2 axis to aging. Cell Death Differ. 2018;25:169-79.

21. Wang X, Kua HY, Hu Y, Guo K, Zeng Q, Wu Q, et al. p53 functions as a negative regulator of osteoblastogenesis, osteoblastdependent osteoclastogenesis, and bone remodeling. J Cell Biol. 2006;172:115-25.

22. Yang Y, Wang C, Zhao K, Zhang G, Wang D, Mei Y. TRMP, a p53-inducible long noncoding RNA, regulates G1/S cell cycle progression by modulating IRES-dependent p27 translation. Cell Death Dis. 2018;9:886.

23. Mantovani F, Collavin L. Mutant $\mathrm{p} 53$ as a guardian of the cancer cell. Cell Death Differ. 2019;26:199-212.

24. Arena G, Riscal R, Linares LK, Le Cam L. MDM2 controls gene expression independently of p53 in both normal and cancer cells. Cell Death Differ. 2018;25:1533-5.

25. di Gennaro A, Damiano V, Brisotto G, Armellin M, Perin T, Zucchetto A, et al. A p53/miR-30a/ZEB2 axis controls triple negative breast cancer aggressiveness. Cell Death Differ. 2018;25: 2165-80.

26. Fang L, Du WW, Lyu J, Dong J, Zhang C, Yang W, et al. Enhanced breast cancer progression by mutant $\mathrm{p} 53$ is inhibited by the circular RNA circ-Ccnb1. Cell Death Differ. 2018;25: 2195-208.

27. Chen Y, Liu K, Shi Y, Shao C. The tango of ROS and p53 in tissue stem cells. Cell Death Differ. 2018;25:639-41.

28. Zhang M, Zhang Y, Xu E, Mohibi S, de Anda DM, Jiang Y, et al. $\mathrm{Rbm} 24$, a target of $\mathrm{p} 53$, is necessary for proper expression of $\mathrm{p} 53$ and heart development. Cell Death Differ. 2018;25:1118-30.

29. Lim Y, De Bellis D, Dorstyn L, Kumar S. p53 accumulation following cytokinesis failure in the absence of caspase-2. Cell Death Differ. 2018;25:2050-2.

30. Lonetto G, Koifman G, Silberman A, Attery A, Solomon H, Levin-Zaidman S, et al. Mutant p53-dependent mitochondrial metabolic alterations in a mesenchymal stem cell-based model of progressive malignancy. Cell Death Differ. 2019;26:1566-81.

31. Boregowda SV, Krishnappa V, Strivelli J, Haga CL, Booker CN, Phinney DG. Basal p53 expression is indispensable for mesenchymal stem cell integrity. Cell Death Differ. 2018;25: 679-92.
32. Amelio I, Melino G. Context is everything: extrinsic signalling and gain-of-function p53 mutants. Cell Death Discov. 2020;6:16.

33. Bar J, Moskovits N, Oren M. Involvement of stromal p53 in tumor-stroma interactions. Semin Cell Dev Biol. 2010;21:47-54.

34. Rubio R, Gutierrez-Aranda I, Saez-Castillo AI, Labarga A, RosuMyles M, Gonzalez-Garcia S, et al. The differentiation stage of p53-Rb-deficient bone marrow mesenchymal stem cells imposes the phenotype of in vivo sarcoma development. Oncogene. 2013;32:4970-80.

35. Bubendorf L, Schopfer A, Wagner U, Sauter G, Moch H, Willi N, et al. Metastatic patterns of prostate cancer: an autopsy study of 1,589 patients. Hum Pathol. 2000;31:578-83.

36. Tataria M, Quarto N, Longaker MT, Sylvester KG. Absence of the p53 tumor suppressor gene promotes osteogenesis in mesenchymal stem cells. J Pediatr Surg. 2006;41:624-32.

37. Geusens PP, Landewe RB, Garnero P, Chen D, Dunstan CR, Lems WF, et al. The ratio of circulating osteoprotegerin to RANKL in early rheumatoid arthritis predicts later joint destruction. Arthritis Rheum. 2006;54:1772-7.

38. Walsh MC, Choi Y. Biology of the RANKL-RANK-OPG System in Immunity, Bone, and Beyond. Front Immunol. 2014;5:511.

39. Lloyd SA, Yuan YY, Kostenuik PJ, Ominsky MS, Lau AG, Morony $\mathrm{S}$, et al. Soluble RANKL induces high bone turnover and decreases bone volume, density, and strength in mice. Calcif tissue Int. 2008;82:361-72.

40. Antonov AV. BioProfiling.de: analytical web portal for highthroughput cell biology. Nucleic Acids Res. 2011;39:W323-327. (Web Server issue)

41. Amelio I, Tsvetkov PO, Knight RA, Lisitsa A, Melino G, Antonov AV. SynTarget: an online tool to test the synergetic effect of genes on survival outcome in cancer. Cell Death Differ. 2016;23:912.

42. Shi Y, Wang Y, Li Q, Liu K, Hou J, Shao C, et al. Immunoregulatory mechanisms of mesenchymal stem and stromal cells in inflammatory diseases. Nat Rev Nephrol. 2018;14:493-507.

43. Pittenger MF, Mackay AM, Beck SC, Jaiswal RK, Douglas R, Mosca JD, et al. Multilineage potential of adult human mesenchymal stem cells. Science. 1999;284:143-7.

44. Haynesworth SE, Goshima J, Goldberg VM, Caplan AI. Characterization of cells with osteogenic potential from human marrow. Bone. 1992;13:81-88.

45. Ren G, Su J, Zhang L, Zhao X, Ling W, L'Huillie A, et al. Species variation in the mechanisms of mesenchymal stem cell-mediated immunosuppression. Stem Cells. 2009;27:1954-62.

46. Honda Y, Ding X, Mussano F, Wiberg A, Ho CM, Nishimura I. Guiding the osteogenic fate of mouse and human mesenchymal stem cells through feedback system control. Sci Rep. 2013; 3:3420.

47. Xu J, Li Z, Hou Y, Fang W. Potential mechanisms underlying the Runx2 induced osteogenesis of bone marrow mesenchymal stem cells. Am J Transl Res. 2015;7:2527-35.

48. Nakamura M, Udagawa N, Matsuura S, Mogi M, Nakamura H, Horiuchi $\mathrm{H}$, et al. Osteoprotegerin regulates bone formation through a coupling mechanism with bone resorption. Endocrinology. 2003;144:5441-9.

49. Liu Y, Elf SE, Asai T, Miyata Y, Liu Y, Sashida G, et al. The p53 tumor suppressor protein is a critical regulator of hematopoietic stem cell behavior. Cell Cycle. 2009;8:3120-4.

50. Ell B, Mercatali L, Ibrahim T, Campbell N, Schwarzenbach H, Pantel K, et al. Tumor-induced osteoclast miRNA changes as regulators and biomarkers of osteolytic bone metastasis. Cancer Cell. 2013;24:542-56.

51. Clover J, Dodds RA, Gowen M. Integrin subunit expression by human osteoblasts and osteoclasts in situ and in culture. J Cell Sci. 1992;103:267-71. 
52. Dillard PR, Lin MF, Khan SA. Androgen-independent prostate cancer cells acquire the complete steroidogenic potential of synthesizing testosterone from cholesterol. Mol Cell Endocrinol. 2008;295:115-20.

53. Rodan SB, Rodan GA, Simmons HA, Walenga RW, Feinstein MB, Raisz LG. Bone resorptive factor produced by osteosarcoma cells with osteoblastic features is PGE2. Biochem biophys Res Commun. 1981;102:1358-65.

54. Rodan GA, Martin TJ. Role of osteoblasts in hormonal control of bone resorption-a hypothesis. Calcif Tissue Int. 1981;33: 349-51.

55. Yasuda H, Shima N, Nakagawa N, Mochizuki SI, Yano K, Fujise $\mathrm{N}$, et al. Identity of osteoclastogenesis inhibitory factor (OCIF) and osteoprotegerin (OPG): a mechanism by which OPG/OCIF inhibits osteoclastogenesis in vitro. Endocrinology. 1998;139: 1329-37.

56. Santhanam U, Ray A, Sehgal PB. Repression of the interleukin 6 gene promoter by $\mathrm{p} 53$ and the retinoblastoma susceptibility gene product. Proc Natl Acad Sci USA. 1991;88:7605-9.

57. Menendez D, Inga A, Resnick MA. The expanding universe of p53 targets. Nat Rev Cancer. 2009;9:724-37.

58. Zhang L, Yu D, Hu M, Xiong S, Lang A, Ellis LM, et al. Wildtype p53 suppresses angiogenesis in human leiomyosarcoma and synovial sarcoma by transcriptional suppression of vascular endothelial growth factor expression. Cancer Res. 2000;60: 3655-61.

59. Zhai W, Comai L. Repression of RNA polymerase I transcription by the tumor suppressor p53. Mol Cell Biol. 2000;20:5930-8.

60. Rocha S, Martin AM, Meek DW, Perkins ND. p53 represses cyclin D1 transcription through down regulation of $\mathrm{Bcl}-3$ and inducing increased association of the p52 NF-kappaB subunit with histone deacetylase 1. Mol Cell Biol. 2003;23:4713-27.

61. Mizuno A, Amizuka N, Irie K, Murakami A, Fujise N, Kanno T, et al. Severe osteoporosis in mice lacking osteoclastogenesis inhibitory factor/osteoprotegerin. Biochem Biophys Res Commun. 1998;247:610-5.

62. Attardi LD, Jacks T. The role of $\mathrm{p} 53$ in tumour suppression: lessons from mouse models. Cell Mol life Sci CMLS. 1999;55: $48-63$.

63. Huang Y, Li Q, Zhang K, Hu M, Wang Y, Du L, et al. Single cell transcriptomic analysis of human mesenchymal stem cells reveals limited heterogeneity. Cell Death Dis. 2019;10:368.

64. Secchiero P, Corallini F, Rimondi E, Chiaruttini C, di Iasio MG, Rustighi A, et al. Activation of the p53 pathway down-regulates the osteoprotegerin expression and release by vascular endothelial cells. Blood. 2008;111:1287-94. 